\title{
Crafting Conscious Employee Engagement through Wellbeing: A Key Differentiator to Long-Term Organisational Success within the Hospitality Industry
}

Poonam Singh Veliath*, Rashmi Koppar ${ }^{\dagger}$, Varynia Wankhar* and Ritu Chawla Mathur ${ }^{\S}$

\section{Abstract}

Discussions on pandemics that hit the human race have dominated the scientific research world, on the contrary, due to the developments in technology and globalisation the work environment has evolved into a complex space and for this reason, there is a wide research gap on how the workforce can get back to normal or cope with an ever-changing pandemic phenomenon. The objectives of the current paper are aligned to identify the impact of Covid-19 on different levels of the employees' life, to analyse the effect on mental health and wellbeing, and to formulate a relationship between mindful employee engagement and its impact on organisational success. The current scenario requires the employees to continue working from home for the businesses to sustain themselves in the future. By reviewing 20 research articles, an understanding is developed of the remote-

\footnotetext{
*Hospitality Consultant; Veliath.poonamingh@gmail.com

† Co - Founder \& Director, 95hm Learning Solutions;

rashmikoppar@yahoo.com

‡Department of Hotel Management, CHRIST (Deemed to be University) Central Campus, Bangalore, Karnataka, India; Varynia.rw@gmail.com \$Hospitality Consultant, Managing Partner, Prognosis Global Consulting and National, Vice President, WICCI - Hospitality Tourism; Rchawla@prognosisglobal.in
} 
work model and its positive and negative impacts on employees as well as organisations. Using a semistructured questionnaire to interview service industry professionals, data has been gathered. Using a semistructured analysis the authors aim to illustrate the pandemic's effects from the employees' perspective. The researchers found three significant findings: loyalty to self-preservation, mindfulness to address mental health and improve performance and success of organisations during the pandemic depends on a purpose-driven culture.

Keywords: Remote-working, Mindfulness, Wellbeing, Selfpreservation

\section{Introduction}

The Indian hospitality sector was expected to grow significantly post 2020, however, the pandemic of 2019 has the industry on haul and suffering from a crisis (Confederation of Indian Industry, 2020). Since 1950 the World Health Organisation has been focusing on occupational health, the WHO emphasised that there exists a correlation between the health of the employees and the performance of the business, that is the work and workplace affect the employees' mental and physical health, which in turn, affect business performance (Szabo and Juhasz 2019).

Studies conducted by some researchers such as (Aguilera et al., 2007; Watkins et al., 2014) depict that the pandemic has led to increased fear of losing jobs and income along with increased health problems resulting in the growing importance of selfinterested needs.

Business leaders face ethical dilemmas when the pandemic erodes their ability to make the right decision and they end up making ego-based choices benefiting themselves rather than their coworkers resulting in ethical egoism (Burgess-Jackson, 2013).

A recent study done by Buffer.com (2019) revealed three main concerns of employees working remotely: (a) loneliness (b) inability to unplug and (c) lack of communication and collaboration. 
The "new normal"-working virtually from home has changed the way people work, instead of work being confined to a specific location and time it has now spilled over to the four walls of the homes; furthermore, impacting family life that has also ceased to be "normal". To delve into the impact of a pandemic such as the Covid-19 on the employees of the hospitality sector, the main objectives of this paper are to identify the impact of Covid-19 on the different levels of the employees' life, to analyse the effect on mental health and wellbeing and to formulate a relationship between mindful employee engagement and its impact on organisational success.

\section{Review of Literature}

\subsection{Employee wellbeing}

Social distancing norms have impacted an individual's wellbeing that comes from having social relationships. At the industry level, the hospitality industry has been one of the most hit by the pandemic, the sense of distrust towards this industry fuels more stress for the hospitality employees (Ryff, 2019). As per the study done by Agarwal (2021), adding on to the frustration and stress on the family level are several factors, such as (a) workload around the house, (b) living solo, (c) difficulties in relationships, (d) members in the family increasing their demands, and (e) poor accommodation. At an organisational level, the employee's wellbeing is affected by various factors such as (a) overburdening workload, (b) lesser work, (c) unstable job security, (d) job-related risks, (e) monetary risks and (f) lack of support in the form of technology to work from home (Agarwal, 2021).

The job demand resource model proposed by (Demerouti et al., 2001) predicts the organisational outcome through two processes (i) health impairment process: the job demands predict job strain, in turn predicting organisational outcome; (ii) motivational process: here the resources predict the engagement and this, in turn, predicts the organisational outcome.

Hence, organisations in their search for strategic ends to survive the Covid-19 pandemic turbulence must also explore more compassionate management-leadership roles that empathise with 
the employees by caring, listening, supporting and understanding their plight during these tough times (Gallagher, 2020).

\subsection{Employee Engagement}

As early as 1990 employee engagement was mentioned in the works of Kahn (1990). The term employee engagement refers to "a positive, fulfilling, work-related state of mind that is characterised by vigour, dedication, and absorption. Rather than a momentary and specific state, engagement refers to a more persistent and pervasive affective-cognitive state that is not focused on any particular object, event, individual, or behaviour"(Schaufeli et al., 2002).

An employee makes the personal decision of engagement chosen for their reasons, therefore management must understand these reasons from the individual, team and unit's perspective (Harter et al., 2002). Employees who are engaged find a positive return on investment (ROI) in performing the work, are not afraid to show their true self and most importantly they feel like they possess the physical, psychological and emotional recourses required (Kahn, 1990).

The human mind frequently drifts to past events or future events, hence essentially organisations should cultivate a mindful approach more so during remote working where employees are surrounded by distractions (Killingsworth and Gilbert, 2010). According to researchers (Chiesa and Serretti, 2009), the techniques followed in meditation enhances mindfulness. A study done by Gaiswinkler and Unterrainer (2016) concludes that individuals practising yoga daily have higher levels of mindfulness compared to individuals who do not practice yoga. Employees have improved resilience resulting from mindfulness leading to better performance at the job (Kroon et al., 2015).

A study suggests an approach that is top-down and bottom-up influencing the employee engagement - (a) top-down approach: includes the organisational level wherein the HRM systems (Bakker and Albrecht, 2018), which includes practices namely developmental training and performance engagement systems; (b) bottom-up approach: employees influence their engagement level 
by making physical and cognitive changes to their routine jobs also known as job crafting (Wrzesniewski and Dutton, 2001).

\subsection{Organisation Success}

A survey conducted by a research company shows that many companies such as Facebook are planning to continue the remote work model even after the pandemic (Gartner Inc Survey, 2020). According to a definition by Bailey and Kurland (2002)-remote work is defined as "working outside the conventional workplace and communicating by way of telecommunications or computerbased technology". According to Golden and Gajendran (2019) highly, complex work tasks are better executed in a remote work setting where the employee is highly engaged not distracted by the social setting as in the usual work environment. Kerber et al. (2004) insist that employees who are in constant communication with each other stay committed to team goals. Trust is another major factor that plays a role in the remote working model affecting the employee's relationship with the organisation, in a trustworthy environment decisions are made faster and creativity is encouraged (Derven, 2007). As observed in research done by Hyland et al., (2015) many contemporary organisations have seen the benefits of implementing mindfulness training ranging from enhanced perception to behavioural approach of employees and productivity. Organisations such as Apple, Facebook, Microsoft, Goldman Sachs, Twitter etc., offer their employees mindfulness programmes (Vonderlin et al., 2020).

\section{Research Methodology}

To delve into the impact of a pandemic such as the Covid-19 on the employees of the hospitality sector, this paper's main objectives are to identify the impact of Covid-19 on the different levels of the employees' life, to analyse the effect on mental health and wellbeing, and to formulate a relationship between mindful employee engagement and its impact on organisational success. The current paper utilised semi-structured interview questions and targeted service industry professionals due to the current social 
distancing norms. A hybrid model of interviewing was used, wherein the interviewees were interviewed through telephonic conversation and through a Google form survey that included a set of 25 open-ended questions. Using the non-probability sampling technique, the researchers approached a total of 100 respondents, out of which 35 respondents were willing to participate in the survey. The respondents were from different parts of India mainly from tire 1 and tier 2 cities.

\section{Analysis and Interpretation}

The collected data were transcribed into Nvivo12 qualitative data analysis software, the following section displays the results obtained from the software. The researcher formulated three themes from the theoretical background through a thematic analysis of the data: (i) Employee Wellbeing, (ii) Employee Engagement and (iii) Organisational success. These three themes were then used to construct the semi-structured interview questionnaire.

Theme 1: Employee Wellbeing

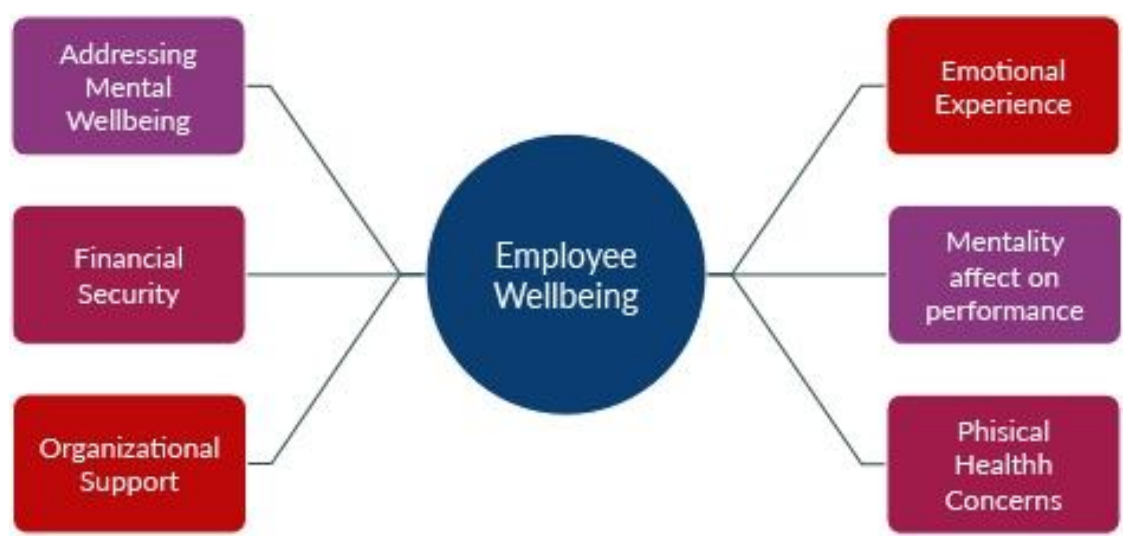

Figure 1: The image illustrates the different levels at which the employee's well-being is affected.

(Source: Author's illustration using Nvivo12) 
Figure 1 shows the first theme Employee Wellbeing during the pandemic is affected by various factors such as the emotional experience, physical health concerns, mental wellbeing, financial security and support from the organisation itself.

Results from the interviews reveal that in light of emotional experience a majority of the respondents felt negative emotions such as paranoid, afraid, scared and frustrated. Quoted below are some of the emotional experiences expressed by the respondents:
"I've been scared and unsure about everything. Lots of thoughts about everything is doomed and not feeling happy or stable. It's been a frightening time with no hope." (R04)
"Felt a little insecure considering the magnitude of the pandemic, for self family and colleagues". (R07)

Conversely, although many of the respondents showed an array of negative emotions there was a handful who saw a silver lining. The below quotes show that employees who have the support of their organisation and leaders felt more at ease during the tough pandemic times:

"Initially of loss, Later of importance, empowerment and satisfaction emotions are involved while working during Covid-19 pandemic". (R13)

"It is still a traumatic experience working in this unprecedented time. You don't know until when your job is secure and most importantly whether you will be able to reach your goal or not. Being a woman, it's not easy enough to stand out and continue working despite knowing the fact that the people around you would hardly appreciate your efforts put into it. Thankfully, the organisation I am associated with has always lent me hand of support and encouragement which has kept me going." (R16)

"Initially I was scared in the beginning of the pandemic, however later I took this as an opportunity to showcase my performance in absence of the managers." (R23) 


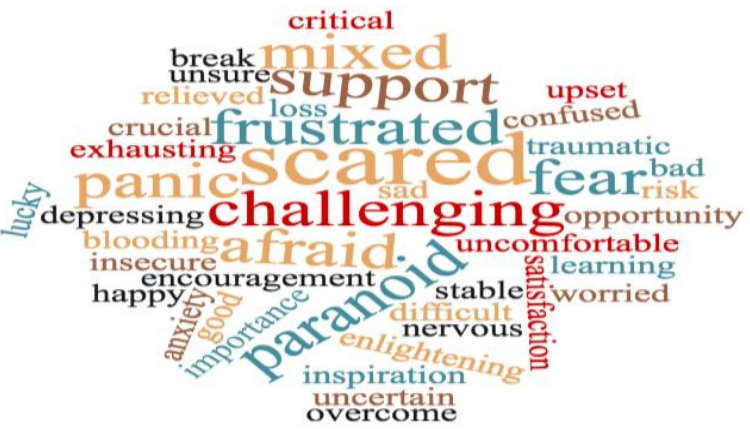

Figure 2: Shows the emotional experience of the respondents during the pandemic (Source: Author's illustration using Nvivo12)

Figure 2 illustrates the various emotions that employees felt during the pandemic about their work, health, future and family.

20 out of 35 respondents have mentioned that when it comes to their mental state during the pandemic although surrounded by negative emotions their productivity at work has not been affected, some respondents remarked that remote working has increased their productivity as they get to learn more and show their performance in the absence of their managers' constant supervision. The remaining 15 respondents have expressed that the pandemic situation has made them feel lazy, anxious about the future, over-burdened while juggling between work and family life.

When asked about how the respondents addressed their mental wellbeing during the pandemic most of the respondents mentioned that keeping in touch with their loved ones helped them, also following a healthy lifestyle through exercise and a healthy diet helped them address their mental wellbeing, few other respondents turned to positive thoughts and used technologies such as meditation and yoga to help them cope with the negative effects of the pandemic.

Only 8 out of the 35 respondents had a positive response when asked how has the pandemic affected their financial health and security - the reason is having the support of the organisation they are working in and not being directly affected by the pandemic in fear of contracting the virus. However, most of the respondents expressed that the virus has gravely affected them financially 
especially for the ones who were admitted to the ICU, their life savings were spent on treatment and tackling the aftermath of the virus infection. Respondents also mentioned salary cuts and not being paid for months.

Most of the respondents were satisfied with how their organisation has supported their wellbeing and taken steps to follow the Covid19 protocols:

"The organization has exceeded the expectation considering there were NO to minimum pay cuts, also the organization has kept us engaged with various wellness sessions conducted online which helped a lot apart from regular health checks being conducted, I am highly satisfied with the Covid-19 protocols that are in place for our own and guest safety including regular screening, and sanitizing processes in place" (R07)

"Extremely satisfied with the measures taken by your organization with respect to Covid-19 protocols to ensure employee and guest safety" (R13)

All respondents expressed concerns regarding their health and family members health, the way they addressed it was by following the Covid-19 protocols, getting vaccinated and keeping themselves and their family members active.

Theme 2: Employee Engagement

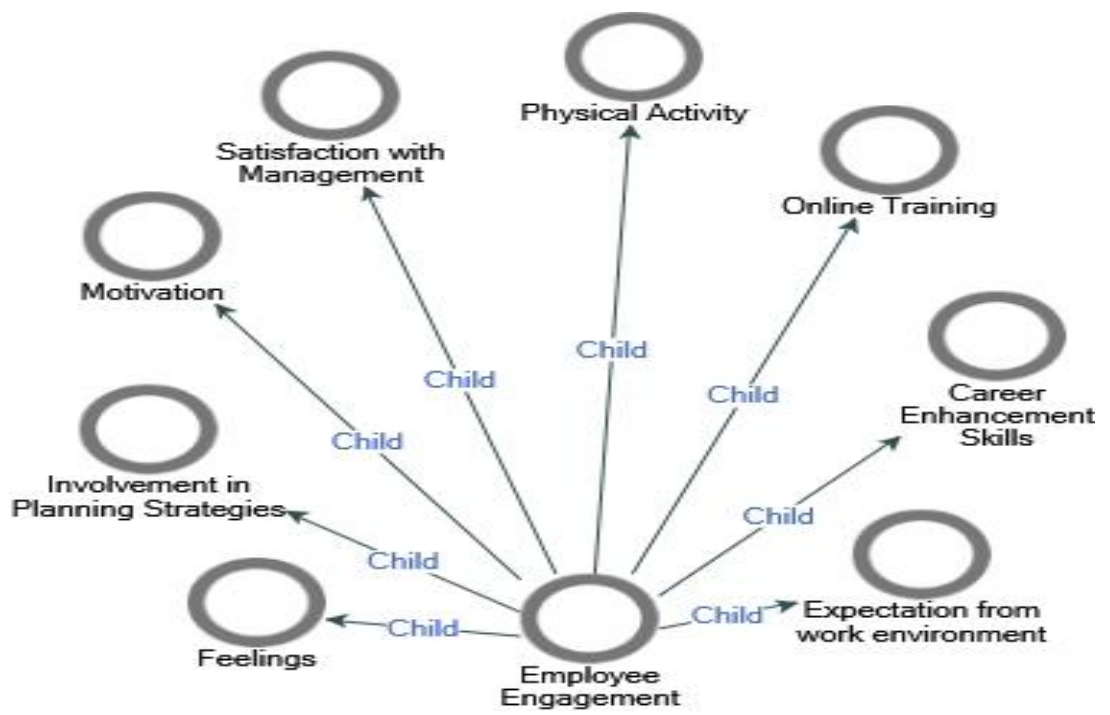


Figure 3: An illustration of factors that affect Employee Engagement during the pandemic. (Source: Authors own illustration using Nvivo12)

The second theme Employee Engagement is affected by different factors both on a personal and organisational level.

Concerning physical activity, most of the respondents take it upon themselves to remain active by walking, cycling, yoga and running. The organisation in this regard supports by providing immunity boosters, Vitamin C, nutritious food for the staff and online training on how to stay active. But a respondent rightly mentions that with long working hours they are too drained to pursue any further physical activity:

"I walk or cycle when I can. No physical activity is particularly provided by the hotel but we are very working long hours (12hours) on the shift which is in itself physically and emotionally exhausting." (R05)

When asked about what would make the employees happy and relaxed at work most respondents mentioned that engaging with their colleagues is what makes them happy. Next comes safety, if organisations can provide a clean sanitised environment and follow the Covid-19 protocols, this will keep their minds at ease. Job security and empathy from the management in tough times were other factors mentioned by the respondents.

When asked about the steps taken by the organisation to motivate employees most of the respondents mentioned the involvement of management in virtual yoga training sessions motivational speeches, CSR activities such as feeding the needy and aiding the affected associates as a motivational factor. Upon being asked what would the respondents additionally expect the organisations to do in terms of motivation, the majority of the respondents displayed signs of satisfaction empathising with the organisations adding that they have done all that was expected. But 5 respondents still mentioned secure salary and job security should be provided during such times.

At the organisational level, the respondents expressed satisfaction with their level of involvement in the organisations' planning phase on how to tackle the pandemic. Conversely, 8 out of 35 respondents were not satisfied with the way the organisation had managed the pandemic situation. 
For the satisfaction levels when it comes to online training programmes majority of the respondents found them satisfactory.

Personally, most of the respondents pursued online learning enhancing their marketing, language and management skills, one respondent however mentions a high level of involvement with the organisation during the learning process:

"We wish the company and help the company to over come from pandemic financial losses by controlling the costing of the department, by making more revenue $\mathcal{E}$ boosting our team members." (R30)

28 respondents felt confident, engaged and motivated as employees in the current pandemic situation and 5 respondents were not quite sure about their feelings.

Theme 3: Organisational Success

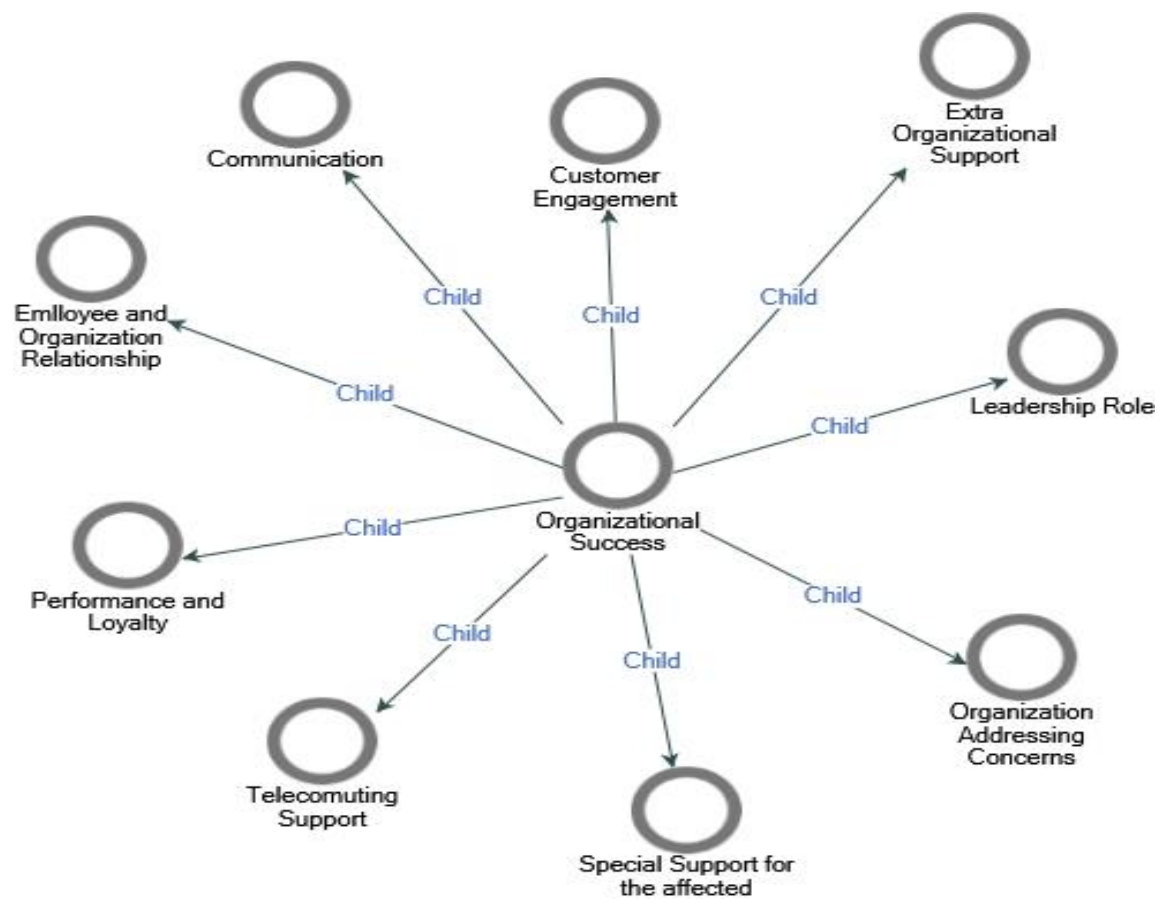

Figure 4: Factors affecting Organisational Success (Source: Authors own illustration using Nvivo12)

The third theme Organisational Success is affected by factors such as loyalty, leadership, communication, employee relationship and 
by the support given by the organisation to the various shareholders and stakeholders of the organisation.

For loyalty, the majority of the employees expressed a sense of belonging and hence remain loyal towards the organisation.

The majority of the respondents agreed that they will benefit personally and professionally to have some extra mental and social support like a professional coach or counsellor from their organisation/hotel during times like the Covid-19 pandemic.

For addressing concerns regarding health, safety and wellbeing within the organisation it was evident from a majority of the responses that organisations do appoint a department/ core team or persons to address the situation.

A majority of the respondents also agree that when it comes to leadership during the pandemic their organisations are doing a good job and are satisfied with the communication they are getting from the organisation about its response to the Covid-19 pandemic. Most organisations provided their employees with telecommuting support.

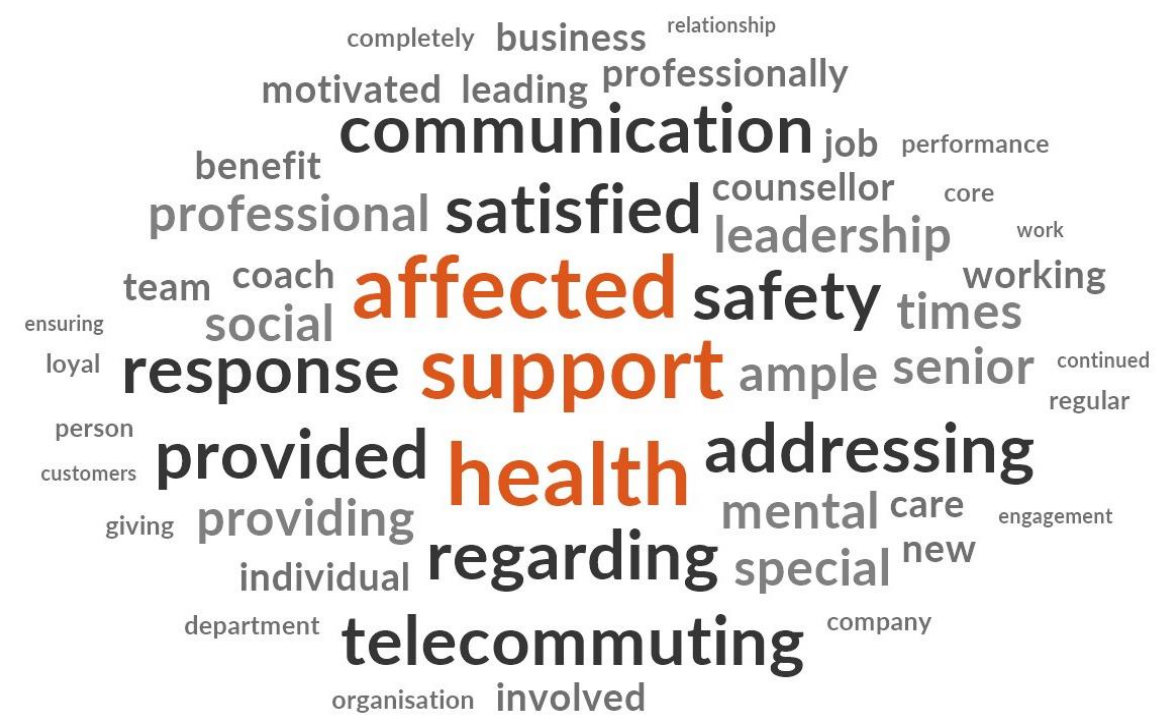

Figure 5: Word Cloud shows the most frequent words used by the respondents for the theme Organisational Success

(Source: Authors own illustration using Nvivo12) 
The pandemic has for most of the respondents strengthened their relationship with the organisation, with stronger bonds built with team members and a sense of belonging and trust developed throughout this difficult period. For employees infected by the virus, there is positive feedback from most respondents that the organisation supports by providing the sick with meals and other additional support.

Continuous virtual interaction with the guests/customer via email, social media and direct calls updating them regarding the status of the hotel with regards to measures taken during pandemic has helped in customer engagement according to the majority of the responses.

\section{Findings and suggestions}

In line with the three main objectives of this paper the findings derived from the analysis have been listed below:

Objective 1: To identify the impact of Covid-19 on the different levels of the employees' life

Finding 1: Self-Preservation over Loyalty:

Upon analysing the data it was found that self-preservation is an individual top priority when hit by a pandemic, employees are most concerned about their health and their family's wellbeing- for this, a major determinant is a financial factor- therefore organisations that offer incentives and financial support during this situation are likely to gain the loyalty of their employees rather than organisations that cut salary and offer less or no support for their employees.

Objective 2: To analyse the effect of the Covid-19 on employees' mental health and wellbeing

Finding 2: Mindfulness to address mental health and improve performance:

An important finding throughout this paper is the importance of mindfulness activities such as yoga and meditation when it comes to addressing the mental wellbeing of the employees, It is, therefore, more beneficial for 
organisations to take extra time to provide professional yoga and meditation sessions for their employees. Mindfulness helps the employees to be present at the moment and focus on the tasks at hand efficiently separating their minds from distractions that especially occur in the remote work environment.

Objective 3: To formulate a relationship between mindful employee engagement and its impact on organisational success.

Finding 3: The success of organisations during the pandemic depends on a purpose-driven culture.

Findings suggest that organisational success during and post-pandemic depends largely on the culture of the organisation, internal and external CSR activities such as feeding the needy or contributing towards relief in terms of monetary and non-monetary support will keep the employees engaged and inculcate a sense of pride and belonging to such an organisation. A stronger bond is built during such activities and loyalty toward the organisation increases.

\section{Conclusion}

The Covid-19 pandemic has spread fear and anxiety globally affecting the mental wellbeing of individuals from all age groups and backgrounds; especially the employees of the worse hit hospitality industry. Taking into consideration the objectives of this paper, the researchers were able to identify the key differentiators to long-term organisational success within the hospitality industry during tough times such as the Covid-19 pandemic. Hence, in line with the paper's objectives, three significant findings were derived from the paper, first employee loyalty to the organisation is related to self-preservation factors such as monetary and non-monetary incentives. Second, mindfulness and openness to address mental health in continuously improving work performance. Thirdly, the success of any organisation is directly related to mindful employee engagement. 
Based on the above findings the researchers further recommend organisations to reduce working hours and include dedicated timing for employees to engage in physical activities that boosts motivation and mental well-being, additionally, the organisation should have a regular health check for their employees to ensure they are physically and mentally fit.

The scope of the paper was limited only to the hospitality sector and its employees; future research can concentrate on a broader perspective and other types of organisations.

\section{References}

Agarwal, P. (2021). Shattered but smiling: Human resource management and the wellbeing of hotel employees during Covid-19. International Journal of Hospitality Management, 93, 102765. https://doi.org/10.1016/j.ijhm.2020.102765

Aguilera, R., Rupp, D., Williams, C. and Ganapathi, J. (2007),

"Putting the $S$ back in corporate social responsibility: a multilevel theory of social change in organizations", Academy of Management Review, Vol. 32, No. 3, pp. 836863, available at:

https://doi.org/10.5465/AMR.2007.25275678

Bailey, D. E., \& Kurland, N. B. (2002). A review of telework research: findings, new directions, and lessons for the study of modern work. Journal of Organizational Behavior, 23(4), 383-400. https://doi.org/10.1002/job.144

Bakker, A.B. and Albrecht, S. (2018), “Work engagement: current trends", Career Development International, Vol. 23, No. 1, pp. 4-11.

Burgess-Jackson, K. (2013), "Taking egoism seriously", Ethical Theory and Moral Practice, Vol. 16 No. 3, pp. 529-542, available at: www.jstor.org/stable/24478617 (accessed 12 June 2020).

Chiesa, A. and Serretti, A. (2009), "Mindfulness-based stress reduction for stress management in healthy people: a 
review and meta-analysis", The Journal of Alternative and Complementary Medicine, Vol. 15 No. 5, pp. 593-600.

Demerouti, E., Bakker, A.B., Nachreiner, F., Schaufeli, W. B., 2001. The job demands- resources model of burnout. J. Appl. Psychol. 86 (3), 499-512.

Derven, M. (2007), "The remote connection: leading others from a distance requires set expectations, trust, and unique methods of evaluation", HR Magazine, Vol. 52, No. 3, pp. 111-115.

Estimated Revenue Losses. Retrieved from. https:/ / www.cii.in/PublicationDetail.aspx?enc=6/lnlra7c1 XlKPU0O5MvJtWcrtv6LPYFaLAzELIKJ5I=.

Gaiswinkler, L., \& Unterrainer, H. (2016). The relationship between yoga involvement, mindfulness and psychological wellbeing. Complementary Therapies in Medicine, 26, 123-127. https://doi.org/10.1016/j.ctim.2016.03.011

Gallagher, R. M. (2020). Our Health Is the Public's Health: Pain Management Leadership in the Covid-19 Pandemic. Pain Medicine, 21(7), 1324-1327. https://doi.org/10.1093/pm/pnaa160

Gartner Inc Survey (2020), “Gartner HR Survey reveals $41 \%$ of employees likely to work remotely at least some of the time post coronavirus pandemic", available at: www.gartner.com/en/ newsroom/press-releases/2020-0414-gartner-hr-survey-reveals-41-of-employees-likely-to(accessed 27 April 2020).

Golden, T. D., \& Gajendran, R. S. (2018). Unpacking the Role of a Telecommuter's Job in Their Performance: Examining Job Complexity, Problem Solving, Interdependence, and Social Support. Journal of Business and Psychology, 34(1), 55-69. https://doi.org/10.1007/s10869-018-9530-4

Harter, J. K., Schmidt, F. L., \& Hayes, T. L. (2002). Business-unitlevel relationship between employee satisfaction, employee engagement, and business outcomes: A meta-analysis. Journal of Applied Psychology, 87, 268-279. 
Hyland, P. K., Lee, R.A. and Mills, M. J. (2015), "Mindfulness at work: a new approach to improving individual and organizational performance", Industrial and Organizational Psychology, Vol. 8, No. 4, pp. 576-602.

Kahn, W. A. (1990). Psychological Conditions of Personal Engagement and Disengagement at Work. Academy of Management Journal, 33(4), 692-724. https://doi.org/10.5465/256287

Kerber, K. W. and Buono, A. F. (2004), "Leadership challenges in global virtual teams: lessons from the field", SAM Advanced Management Journal, Vol. 69, No. 4, pp. 4-10.

Killingsworth, M. A. and Gilbert, D. T. (2010), “A wandering mind is an unhappy mind", Science, Vol. 330, No. 6006, p. 932.

Kroon, B., Menting, C. and Woerkom, M. V. (2015), “Why mindfulness sustains performance: the role of personal and job resources", Industrial and Organizational Psychology, Vol. 8, No. 4, pp. 638-642.

Ryff, C. D. (2019). Entrepreneurship and eudaimonic well-being: Five venues for new science. Journal of Business Venturing, 34(4), https://doi.org/10.1016/j.jbusvent.2018.09.003

646-663.

Schaufeli, W. B., Salanova, M., González-romá, V., \& Bakker, A. B. (2002). The Measurement of Engagement and Burnout: A Two Sample Confirmatory Factor Analytic Approach. Journal of Happiness Studies, 3(1), 71-92. https:/ / doi.org/10.1023/a:1015630930326

State of Remote Work 2019. (2019). Buffer. https:/ / buffer.com/state-of-remote-work-2019

Szabo, Agnes, and Peter Juhasz. 2019. Possibilities of Measuring the Value Creation of Workplace Health Programs (in Hungarian). Vezetéstudomány 50: 59-71.

Vonderlin, R., Biermann, M., Bohus, M. and Lyssenko, L. (2020), "Mindfulness-based programs in the workplace: a metaanalysis of randomized controlled trials", Mindfulness, Vol. 11, No. 7, doi: 10.1007/s12671-020-01328-3. 
Watkins, M. B., Ren, R., Umphress, E. E., Boswell, W. R., Triana, M. D. C., \& Zardkoohi, A. (2014). Compassion organizing: Employees' satisfaction with corporate philanthropic disaster response and reduced job strain. Journal of Occupational and Organizational Psychology, 88(2), 436458. https:// doi.org/10.1111/joop.12088

World Health Organization, 2020. Physical and Mental Health Key to Resilience During Covid-19 Pandemic. Retrieved from. https://www.euro.who.int/en/health-to pics/healthemergencies/coronavirus-covid-19/statements/statementphysical-and-mental-health-key-to-resilience-during-covid19-pandemic.

Wrzesniewski, A., \& Dutton, J. E. (2001). Crafting a Job: Revisioning Employees as Active Crafters of Their Work. Academy of Management Review, 26(2), 179-201. https:/ / doi.org/10.5465/amr.2001.4378011 